\title{
PROTOTYPE LENGAN ROBOT BERBASIS ARDUINO DENGAN MENGGUNAKAN ALGORITMA KINEMATICS
}

\author{
Salmon $^{1}$, Bartolomius Harpad ${ }^{2}$ \\ STMIK Widya Cipta Dharma ${ }^{1,2}$ \\ Jl. M. Yamin No.25, Samarinda \\ Sur-el : salmon@wicida.ac.id ${ }^{1}$, harpad@wicida.ac.id ${ }^{2}$
}

\begin{abstract}
Robot arms, designed and made by humans with the aim to replace human positions in doing heavy and repetitive work. Besides the robot arm used in the automotive industry, it can also be applied to other manufacturing industries. In designing and processing robotic arms, Kinematics and Arduino algorithms are needed. In making a robot arm we need an algorithm, the Kinematics algorithm, which is one branch of study that studies the geometry of motion, so that sometimes this study is considered a direct branch of mathematics. The results of this research are the Arduino-based Robot Arm Prototype Using Kinematics Algorithm.
\end{abstract}

Keywords: kinematics algorithm, Arduino, prototype, robot arm.

\begin{abstract}
Abstrak: Lengan robot, didesain dan dibuat oleh manusia dengan tujuan untuk menggantikan posisi manusia dalam mengerjakan pekerjaan yang berat dan berulang-ulang. Lengan robot selain digunakan dalam industry otomotif, juga dapat diterapkan pada industry manufaktur yang lain. Dalam merancang dan memproses lengan robot diperlukan algoritma Kinematics dan Arduino. Dalam membuat lengan robot diperlukan algoritma yaitu algoritma Kinematics yang merupakan salah satu cabang studi yang mempelajari geometri tentang gerakan, yang sehingga terkadang studi tentang ini dianggap sebagai cabang langsung dari matematika. Hasil dari penelitian ini adalah dibuatnya Prototype Lengan Robot Berbasis Arduino Dengan Menggunakan Algoritma Kinematics.
\end{abstract}

Kata kunci: algoritma kinematics, arduino, prototype, lengan robot

\section{PENDAHULUAN}

Robot berasal dari bahasa Czech, Robota, yang berarti pekerja. Kata robot diperkenalkan dalam bahasa Inggris pada tahun 1921 oleh Wright Karel Capek pada suatu drama, Rossum's Universal Robots. Robot adalah mesin hasil rakitan karya manusia yang mampu bekerja terus- menerus tanpa mengenal lelah. Pada awalnya robot diciptakan sebagai pengganti pekerja manusia, akan tetapi untuk jangka waktu ke depan robot akan mampu mengambil alih posisi manusia sepenuhnya dan bahkan mengganti ras manusia dengan beragam jenis robot. saat ini hampir semua industri manufaktur menggunakan robot. Hal itu karena biaya operasional per jam untuk robot jauh lebih murah dibandingkan menggunakan tenaga manusia. Robot pada awalnya hanya digunkan untuk melakukan fungsi spesifik, misalnya pengecoran, penyolderan, atau yang lain, tetapi saat ini sudah banyak robot yang dapat melakukan banyak fungsi. Tren saat ini ialah robot yang membantu kerja manusia, seperti model robot dari MIT, dimana beban berat seorang tentara dibantu dengan pergelangan kaki yang kuat dari robot $[1,8]$.

Lengan robot, didesain dan dibuat oleh manusia dengan tujuan untuk menggantikan posisi manusia dalam mengerjakan pekerjaan yang berat dan berulang-ulang. Lengan robot selain digunakan dalam industry otomotif, juga 
dapat diterapkan pada industry manufaktur yang lain. Dalam merancang dan memproses lengan robot diperlukan algoritma Kinematics dan Arduino.

Arduino merupakan platform yang terdiri dari software dan hardware. Hardware Arduino sama dengan mikrokontroler pada umumnya hanya pada arduino ditambahkan penamaan pin agar mudah diingat. Software Arduino merupakan perangkat lunak sumber terbuka sehingga dapat di download secara gratis. Software ini digunakan untuk membuat dan memasukkan program ke dalam Arduino. Pemrograman Arduino tidak sebanyak tahapan mikrokontroler konvensional karena Arduino sudah didesain mudah untuk dipelajari, sehingga para pemula dapat mulai belajar mikrokontroler dengan Arduin. Arduino juga merupakan kit elektronik atau papan rangkaian elektronik sumber terbuka yang di dalamnya terdapat komponen utama yaitu sebuah chip mikrokontroler dengan jenis $A V R$ dari perusahaan Atmel [6 - 7].

Dalam membuat lengan robot diperlukan algoritma yaitu algoritma Kinematics yang merupakan salah satu cabang studi yang mempelajari geometri tentang gerakan, yang sehingga terkadang studi tentang ini dianggap sebagai cabang langsung dari matematika. Terdapat definisi lain bahwa Kinematics adalah cabang dari mekanika klasik yang menggambarkan tentang pergerakan sebuah titik, pergerakan sebuah objek, atau juga pergerakan dari grup dari banyak objek tanpa mempedulikan tentang masa dari objek tersebut dan juga gaya yang menyebabkan objek tersebut bergerak [2,9]. Berdasarkan latar belakang diatas, penggunaan algoritma Kinematics dan Arduino sangat tepat dalam membangun prototype lengan robot.

\section{METODOLOGI PENELITIAN}

Metodologi penelitian ini berisikan teori yang berkaitan dengan model pengembangan waterfall dengan menggunakan algoritma Kinematics.

\subsection{Model Waterfall}

Model waterfall adalah model klasik yang bersifat sistematis, berurutan dalam membangun software. Nama model ini sebenarnya adalah "Linear Sequential Model". Model ini sering disebut juga dengan "classic life cycle" atau metode waterfall. Model ini termasuk ke dalam model generic pada rekayasa perangkat lunak dan pertama kali diperkenalkan oleh Winston Royce sekitar tahun 1970 sehingga sering dianggap kuno, tetapi merupakan model yang paling banyak dipakai dalam Software Engineering (SE). Model ini melakukan pendekatan secara sistematis dan berurutan. Disebut dengan waterfall karena tahap demi tahap yang dilalui harus menunggu selesainya tahap sebelumnya dan berjalan berurutan [5].

Fase-fase dalam Waterfall Model sebagai berikut:

1. Analysis, Sebelum memulai pekerjaan yang bersifat teknis, analisis sangat diperlukan untuk memahami dan mencapai tujuan yang ingin dicapai. Adapun analisi yaitu meliputi inisialisasi proyek, seperti menganalisis permasalahan yang dihadapi dan 
mengumpulkan data-data yang diperlukan, serta membantu mendefinisikan fitur dan fungsi software. Pengumpulan data-data tambahan bisa juga diambil dari jurnal, artikel, dan internet.

2. Design. Tahapan ini adalah tahap perancangan dan permodelan arsitektur sistem yang berfokus pada perancangan struktur data, arsitektur software, tampilan interface, dan algoritma program. Tujuannya untuk lebih memahami gambaran besar dari apa yang akan dikerjakan.

3. Code. Tahapan Code ini merupakan proses penerjemahan bentuk desain menjadi kode atau bentuk/bahasa yang dapat dibaca oleh mesin.

4. Test. Setelah pengkodean selesai, dilakukan pengujian terhadap sistem dan juga kode yang sudah dibuat. Tujuannya untuk menemukan kesalahan yang mungkin terjadi untuk nantinya diperbaiki.

Setiap fase dilakukan secara berurutan mulai dari langkah pertama sampai langkah terakhir, setiap langkah yang telah selesai dikerjakan harus dilakukan pengkajian ulang, tertera dalam alur penelitian pada Gambar. 1.

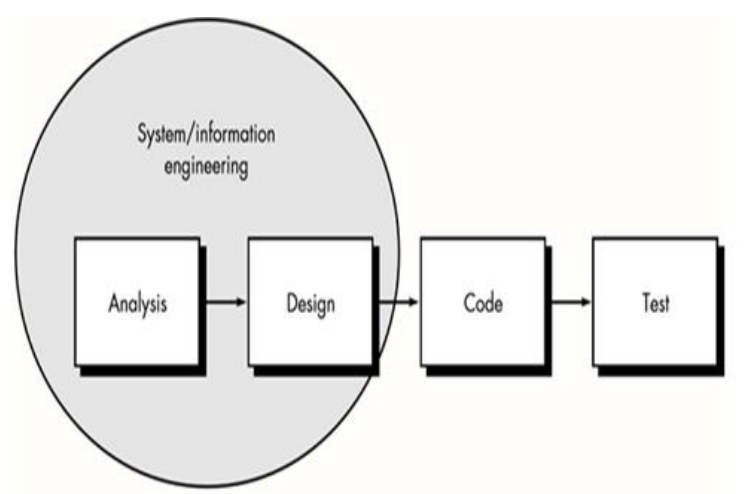

Gambar. 1 Alur Penelitian klasik yang menggambarkan tentang pergerakan sebuah titik, pergerakan sebuah objek, atau juga pergerakan dari grup dari banyak objek tanpa mempedulikan tentang masa dari objek tersebut dan juga gaya yang menyebabkan objek tersebut bergerak [2]. Didalam algortima Kinematika terdapat Forward Kinematics dan Inverse Kinematics yang terlihat pada gambar 2.

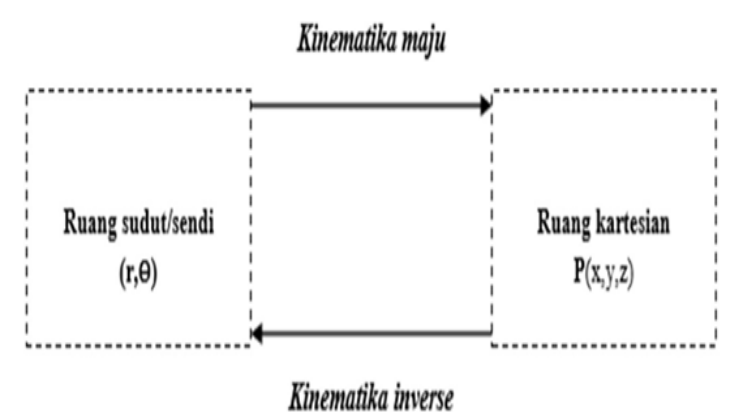

Gambar 2. Forward Kinematics dan Inverse Kinematics

\section{a. Forward Kinematics (FK)}

Forward Kinematics adalah algoritma yang digunakan untuk menghitung pada koordinat mana sebuah titik berada dengan mengetahui panjang lengan beserta sudutsudutnya [4].

\section{b. Inverse Kinematics (IK)}

Inverse Kinematics merupakan kebalikan dari Forward Kinematics. Apabila pada Forward Kinematics kita harus mencari titik end-effector pada koordinat kartesius berdasarkan panjang tiap bagian lengan dan sudut yang diciptakannya, Inverse Kinematics justru digunakan untuk mencari sudut yang dihasilkan tiap lengan berdasarkan panjang setiap bagian lengan dan titik end-effector pada koordinat kartesius [3].

\subsection{Algoritma Kinematika}

Kinematika adalah cabang dari mekanika 


\subsection{Arduino}

Arduino adalah kit elektronik atau papan rangkaian elektronik sumber terbuka yang di dalamnya terdapat komponen utama yaitu sebuah chip mikrokontroler dengan jenis $A V R$ dari perusahaan Atmel [6]. Pada Arduino terdapat Hardware Arduino dan Software Arduino seperti penjelasan dibawah ini.

\section{a. Hardware Arduino}

Arduino merupakan platform sumber terbuka baik secara hardware dan software. Arduino terdiri dari mikrokontroler megaAVR seperti ATmega8, ATmega168, ATmega328, ATmega1280, dan ATmega2560 dengan menggunakan kristal osilator $16 \mathrm{MHz}$, namun ada beberapa tipe Arduino yang menggunakan kristal osilator $8 \mathrm{MHz}$. Catu daya yang dibutuhkan untuk men-supply minimum sistem Arduino cukup dengan tegangan 5 VDC. Port Arduino untuk seri Atmega terdiri dari 20 pin yang meliputi 14 pin I/O digital dengan 6 pin dapat berfungsi sebagai output PWM (Pulse Width Modulation) dan 6 pin I/O analog. Kelebihan Arduino adalah tidak membutuhkan external flash programmer karena di dalam chip microcontroller Arduino telah diisi dengan bootloader yang membuat proses upload menjadi lebih sederhana. Untuk koneksi terhadap komputer dapat menggunakan RS232-to-TTL Converter atau menggunakan chip USB ke Serial converter seperti FTDI FT232 [7]. Hardware Arduino terlihat pada gambar 3.

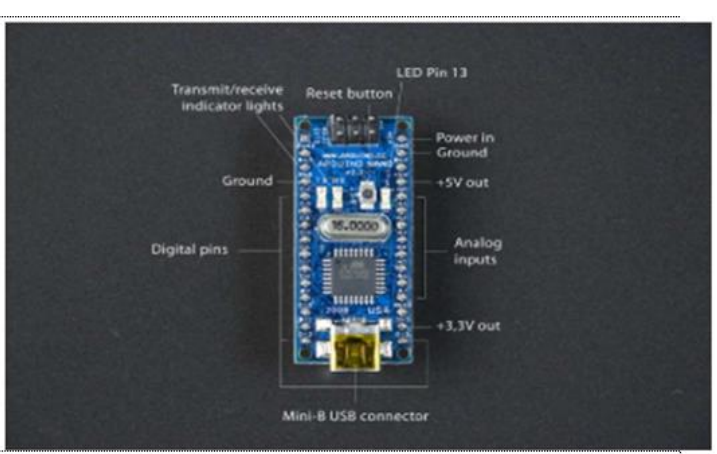

Gambar 3. Bentuk Fisik Arduino Nano

\section{b. Software Arduino}

Arduino diciptakan untuk para pemula bahkan yang tidak memiliki dasar bahasa pemrograman sama sekali karena menggunakan bahasa C++ yang telah dipermudah melalui library. Arduino menggunakan Software Processing yang digunakan untuk menulis program ke dalam Arduino. Processing sendiri merupakan penggabungan antara bahasa $\mathrm{C}++$ dan Java. Software Arduino ini dapat di-install di berbagai operating system (OS)[7].

\section{HASIL DAN PEMBAHASAN}

\subsection{Skematika}

Untuk melihat bagaimana Arduino Nano, Adafruit PCA9685, Bluetooth HC-05 dan servoservo terhubung, bisa dilihat pada skematika seperti pada gambar 4 :

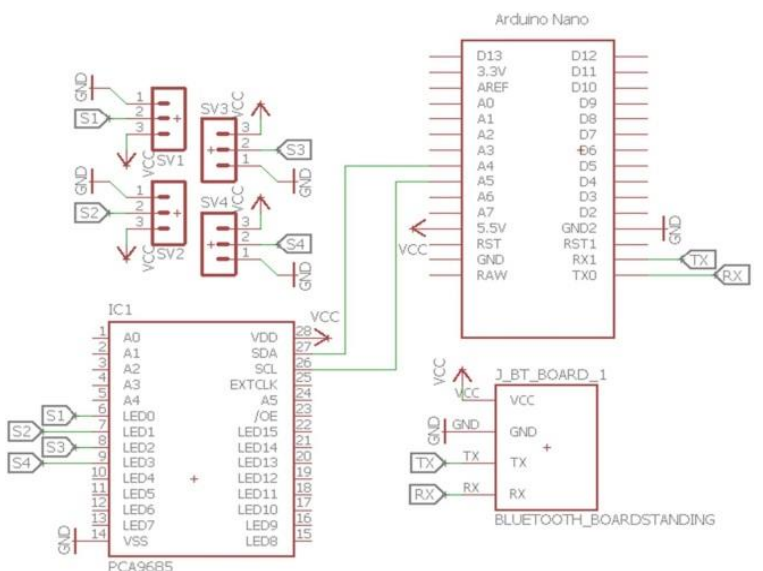

Gambar 4. Skematika perangkat keras 
Pada skematika tersebut terlihat bahwa pin SDA dan SCL pada PCA9685 dihubungkan ke pin A4 dan A5 pada Arduino Nano. Khusus untuk Arduino Nano, pin A4 dan A5 bisa digunakan untuk menggantikan pin SDA dan SCL.

Pin TX dan RX harus dipasang secara terbalik. Maka pin TX pada Bluetooth dihubungkan ke pin RX pada Arduino. Dan pin RX pada Bluetooth dihubungkan ke pin TX pada Arduino.

\subsection{Antarmuka mode FK (kanan) dan mode IK (kiri)}

Adapun tampilan yang nantinya akan dimunculkan pada layar aplikasi RemoteXY adalah seperti gambar 5 .

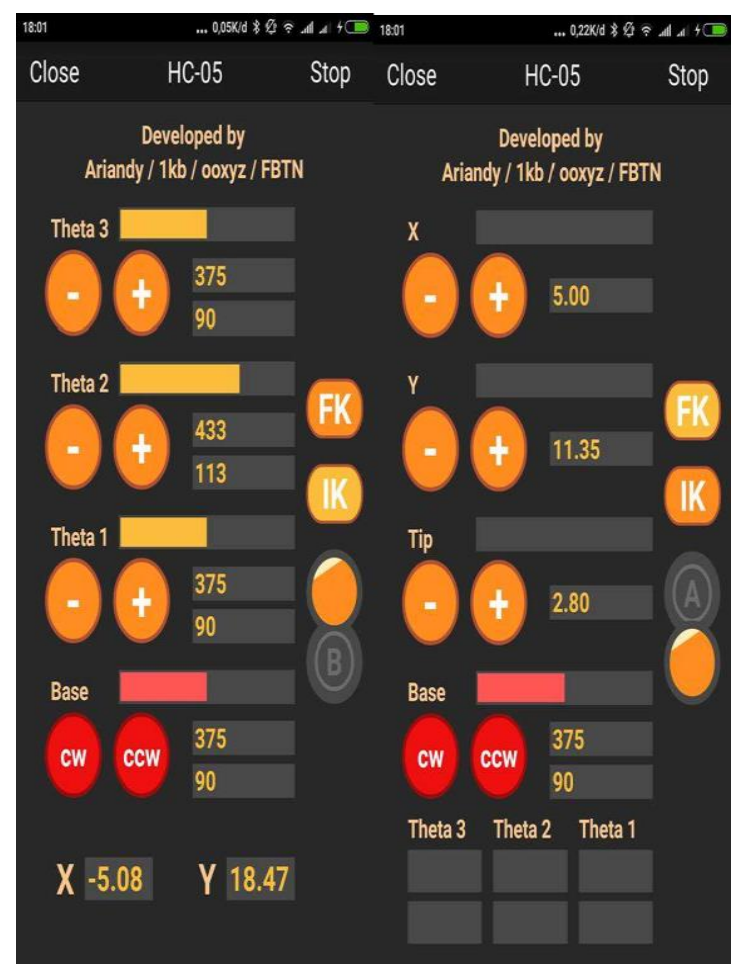

Gambar 5. Antarmuka mode FK (kanan) dan mode IK (kiri)

Antarmuka tersebut dirancang pada website RemoteXY, karena RemoteXY tidak menyediakan aplikasi offline yang dapat digunakan sebagai editor antarmuka.

Pada mode FK, setiap PWM diatur dengan dua tombol, yaitu plus dan minus. Karena ada 3 variabel $\theta$, maka dibutuhkan 6 buah tombol. Sedangkan pada mode IK, setiap variabel (tip, $\mathrm{x}, \mathrm{y}$ ) membutuhkan 2 tombol, maka dibutukan 6 tombol pula. Adapun tombol pada Base hanya sekedar tambahan untuk menggerakkan servo yang berada paling bawah dan bergerak berdasarkan y-axis.

\subsection{Algoritma}

Secara general, kode pada Arduino memiliki struktur yang secara berurutan yaitu inisialisasi, $\operatorname{loop}(), \operatorname{setup}()$. Oleh karena itu, struktur pada program untuk mengoperasikan lengan robot ini adalah seperti gambar 6 .

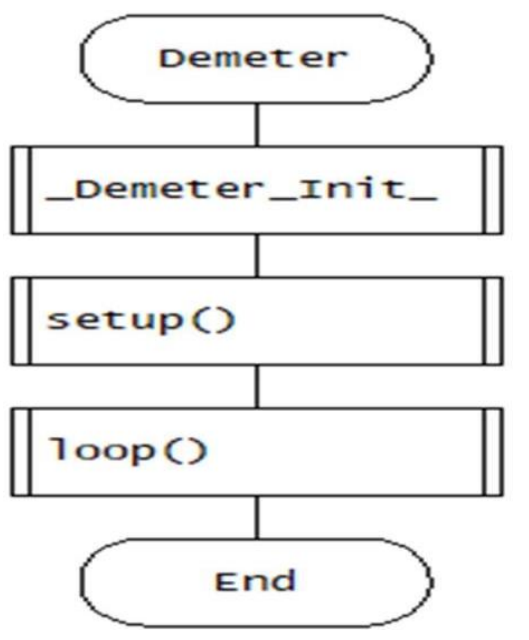

Gambar 6. Struktur Program

Adapun header dari program ini diberi nama Demeter. Dan pada Demeter ada 3 prosedur yaitu_Demeter_Init_, setup() dan loop(). Prosedur_Demeter_Init_ berisi bagian kode dimana isinya adalah inisialisasi. Semua perintah seperti kode dari RemoteXY, <include> dan \#define berada di dalamnya. Juga ada beberapa variabel yang harus dituliskan di 
awal, contohnya, posisi awal lengan.

Pada implementasinya di Arduino, beberapa variabel pada formula yang menggunakan fungsi acos harus dipecah terlebih dahulu menjadi beberapa variabel, karena fungsi acos tidak memperbolehkan nilai integer sebagai input.

\subsection{Perangkat Keras}

Tampilan fisik dari lengan robot yang akan menjadi alat peraga dan pencatunya (Power Supply 5V/5A) seperti gambar 7.

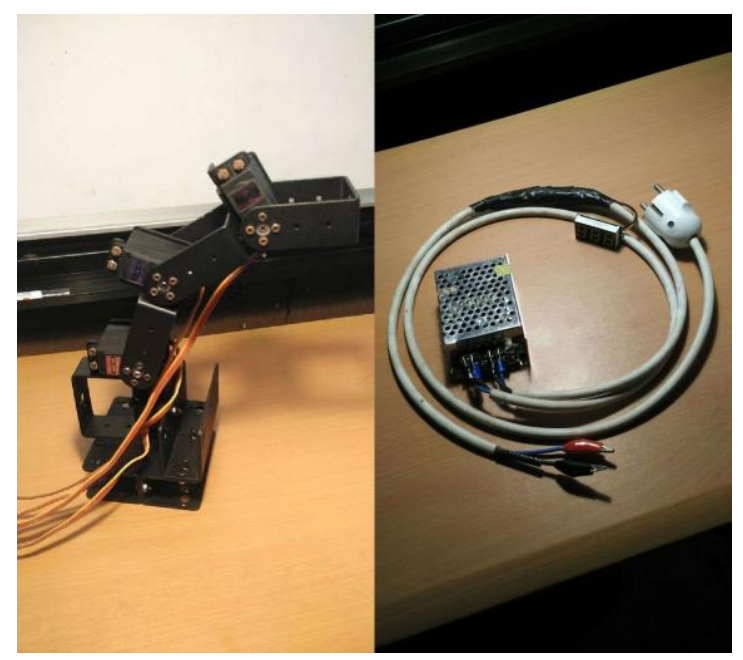

Gambar 7. Lengan Robot dan Pencatunya

Sedangkan perangkat yang akan digunakan untuk menggerakkan lengan tersebut seperti gambar 8 .

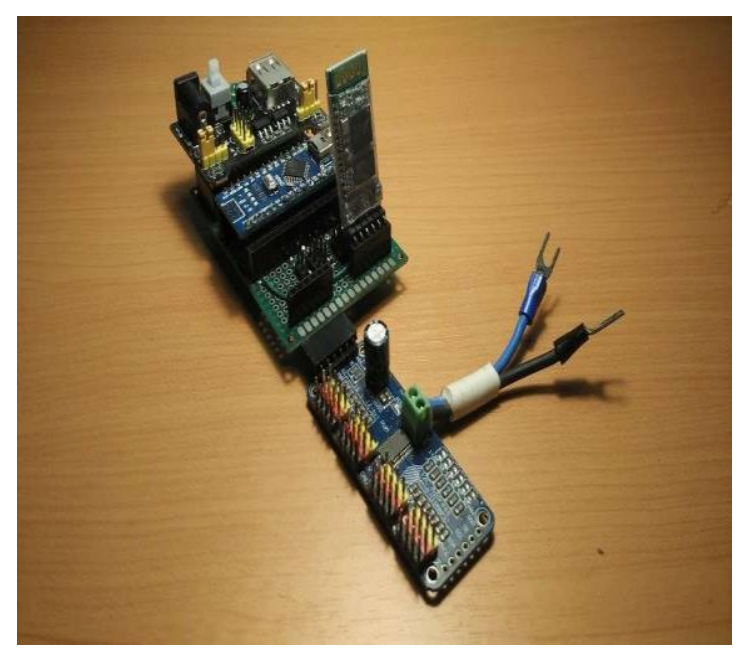

Gambar 8. PCB

\subsection{Penulisan Code dan Simulasi}

Code yang dituliskan pada Arduino IDE akan dilampirkan pada bagian awal lampiran (setelah lembar wawancara). Adapun hasil dari simulasi pada Wolfram Mathemathica seperti gambar 9.

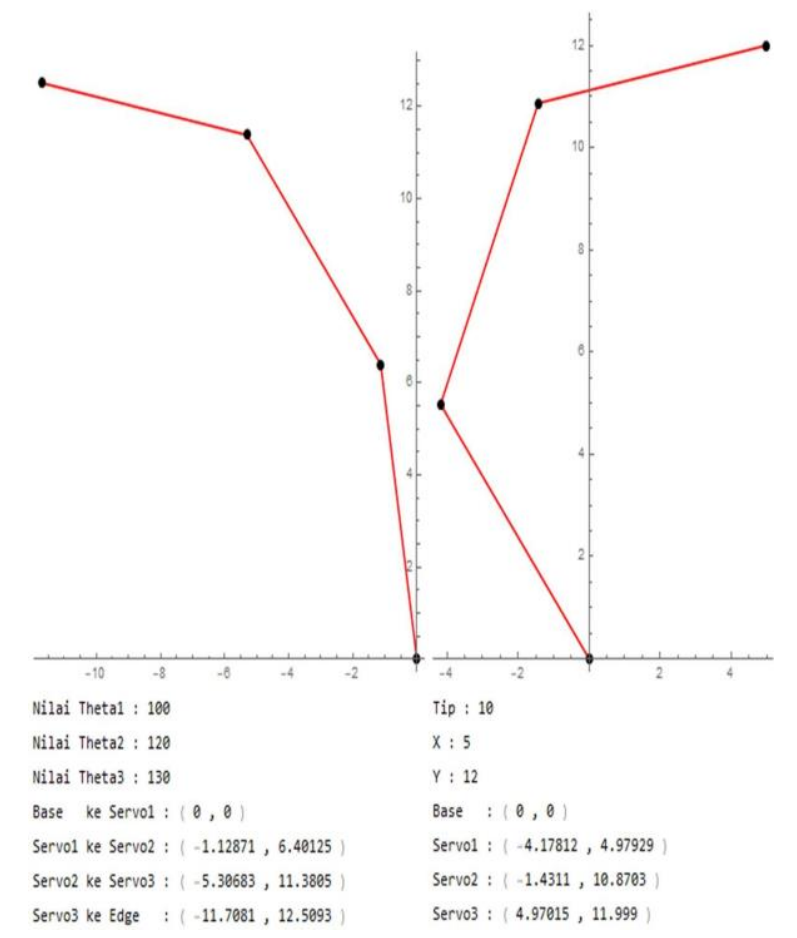

Gambar 9. Simulasi FK dan Analytical IK

Pada simulasi FK, input yang digunakan adalah $\theta_{1}=100, \theta_{2}=120$ dan $\theta_{3}=130$. Untuk simulasi IK, input yang digunakan adalah tip $=$ $10, \mathrm{x}=5, \mathrm{y}=12$. Untuk melakukan simulasi, bisa dilakukan melalui Raspberry Pi 3 atau komputer/laptop (selama komputer/laptop cukup mumpuni untuk menjalankan Wolfram Mathematica). Namun akan lebih disarankan melalui Raspberry Pi 3 karena memiliki spesifikasinya yang cukup dan berlisensi gratis. 


\section{KESIMPULAN}

Dari hasil penelitian dan pembahasan yang telah dilaksanakan maka dapat diambil beberapa kesimpulan yaitu :

1. Penerapan Algoritma Kinematics dilakukan dengan cara mengunggah kode yang telah ditulis ke Arduino. Lengan robot dihubungkan dengan smartphone Android dan RemoteXY sebagai remote controlnya dan Bluetooth sebagai penghubungnya.

2. Implementasi algoritma Kinematics pada lengan robot telah berhasil dilakukan.

3. Algoritma dapat dipangkas beberapa variabelnya apabila memiliki panjang bracket yang sama.

\section{UCAPAN TERIMA KASIH}

Judul Dibiayai oleh Direktorat Riset dan Pengabdian Masyarakat Direktorat Jenderal Penguatan Riset dan Pengembangan Kementerian Riset, Teknologi, dan Pendidikan Tinggi sesuai Dengan Kontrak Penelitian Tahun Anggaran 2020.

\section{DAFTAR PUSTAKA}

[1] Budiharto, Widodo. Membuat Sendiri Robot Cerdas Edisi Revisi. Jakarta : Elex Media Komputindo. 2010

[2] Hibbeler, Russell C. "Kinematics and Kinetics of a Particle". Engineering Mechanics: Dynamics (12th Edition). Upper Saddle River: Prentice Hall. 2009

[3] Hooper, Richard. Learn About Robot. London: LAR. 2008

[4] Kay, Jennifer.Introduction to Homogeneous Transformation \& Robot Kinematics. Glasboro: Rowan University Computer Science Department. 2010

[5] Pressman R. Software Engineering: A Practitioner's Approach Seventh Edition. New York: McGraw Hill. 2010

[6] Santoso, Hari. Panduan Praktis Arduino Untuk Pemula. Trenggalek: Elang Sakti. 2015

[7] Sulaiman, A. Arduino: Mikrokontroler Bagi Pemula Hingga Mahir. Tangerang: Balai Elektronika. 2012

[8] Suyadhi, Taufiq Dwi Septian. $\quad B u k u$ Pintar Robotika. Yogyakarta : Andi Offset. 2010.

[9] Teodorescu, P. P. "Kinematics". Mechanical Systems, Classical Models: Particle Mechanics. Berlin: Springer. 2008 